\title{
TURISMO EM ANÁLISE
}

\section{Motivações para Terceirização de Serviços em Hotéis na Perspectiva das Microfundações das Capacidades Dinâmicas}

Motivaciones para servicios de outsourcing en los hoteles en la perspectiva de los microfundamentos de las capacidades dinámicas

Motivations for Outsourcing Hotel Services under the Microfoundations Perspective of Dynamic Capabilities

Kawana Harue Sato ${ }^{1}$

Heitor Takashi Kato ${ }^{2}$

Tomas Sparano Martins ${ }^{3}$

\section{ESTE ARTIGO FOI RETIRADO}

APÓS OS AUTORES TEREM ASSINADO UMA DECLARAÇÃO DE QUE SE TRATAVA DE TRABALHO INÉDITO, INFORMARAM, DEPOIS DO LANÇAMENTO DESTE NÚMERO, QUE O ARTIGO JÁ HAVIA SIDO PUBLICADO COM OUTRO TÍTULO.

\section{O ARTIGO FOI PUBLICADO EM OUTRO PERIÓDIICO:}

RBTUR Revista Brasileira de de Pesquisa em Turismo Volume 7 número 1 de 2013. Sob o título O Processo de Terceirização de Serviços Hoteleiros.

Recebido em: 13/01/2013 ( $1^{\mathrm{a}}$ versão) $23 / 09 / 2013$ ( $2^{\mathrm{a}}$ versão)

Aprovado em: 05/11/2013

\footnotetext{
${ }^{1}$ Mestre e Bacharel em Administração pela Pontifícia Universitade Católita do Paraná (PUC-PR). Professora na Organização Paranaense de Ensino Técnico (OPET). Brasil. E-mail: kawana.sato@gmail.com.

${ }^{2}$ Doutor e Mestre em Administração de Empresas e Bacharel em Administração pela Fundação Getúlio Vargas (FGV). Professor Titular da PUC-PR. Brasil. E-mail: heitor.kato@pucpr.br.

${ }^{3}$ Doutor e Mestre em Administração pela PUC-PR. Professor da Universidade Positivo e PUC-PR. Brasil. Email: tomas.martins@pucpr.br.
} 